\title{
UTILIDAD DE LOS TEXTOS DEL NUEVO TESTAMENTO PARA LA ENSEÑANZA DEL LATÍN Y EL GRIEGO
}

\author{
Manuel García García - C. Rita Jorge Hernández \\ IES Realejos - IES Mencey Bencomo \\ manugarcia15@gmail.com - carmenritajorgeh@gmail.com
}

A Juan Barreto,

con nuestro cariñoso agradecimiento

por su magisterio.

\section{RESUMEN}

Mediante la explicación de la aplicación práctica en el aula, como recurso didáctico, de un pasaje del evangelio de Juan, se pretende demostrar la utilidad del corpus textual del Nuevo Testamento para la enseñanza de las materias de Latín y Griego en la Educación Secundaria Obligatoria y el Bachillerato.

Palabras ClaVE: Nuevo Testamento, recurso didáctico, fonética, morfosintaxis, semántica, cultura, teología.

\section{UTILITY OF THE NEW TESTAMENT TEXTS FOR TEACHING LATIN AND GREEK}

\section{ABSTRACT}

Through the explanation of the practical application, in the classroom, as a teaching resource, of a passage from the Gospel of John, it is intended to demonstrate the usefulness of the New Testament text corpus for teaching Latin and Greek subjects in Secondary and High School. KEY WORDS: New Testament, teaching resource, fonetic, morphosyntax, semantic, culture, theology.

0. UN PASAJE DEL NUEVO TESTAMENTO: JUAN, 18, 33-38

\section{A. TEXTO ORIGINAL ${ }^{1}$}

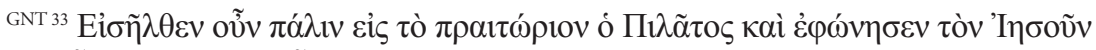

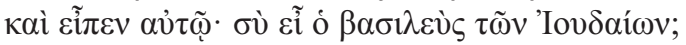

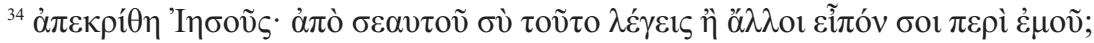

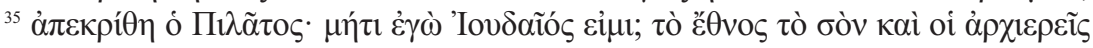

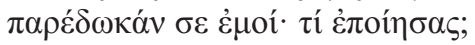




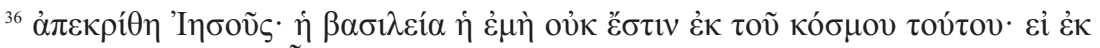

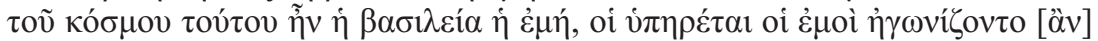

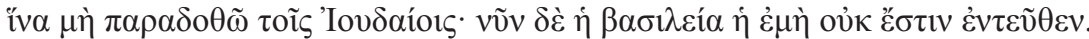

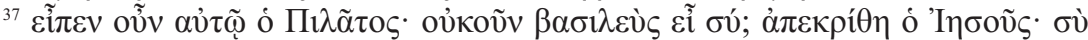

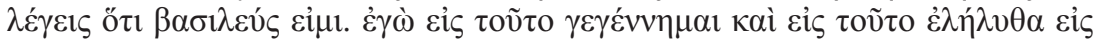

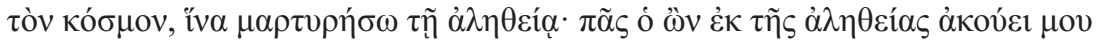
$\tau \tilde{\eta} \varsigma \varphi \omega \vee \tilde{\eta} s$.

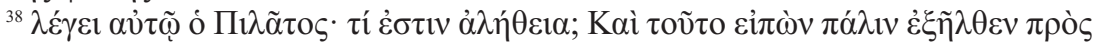

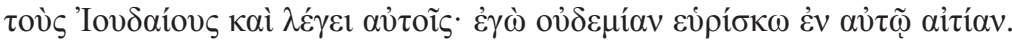

\section{B. VULGATA2}

vul ${ }^{33}$ Introivit ergo iterum in praetorium Pilatus et vocavit Iesum et dixit ei: «Tu es rex Iudaeorum?»

${ }^{34}$ Et respondit Iesus: "A temet ipso hoc dicis an alii tibi dixerunt de me?»

${ }^{35}$ Respondit Pilatus: «Numquid ego Iudaeus sum? Gens tua et pontifices tradiderunt te mihi. Quid fecisti?»

${ }^{36}$ Respondit Iesus: «Regnum meum non est de mundo hoc. Si ex hoc mundo esset regnum meum, ministri mei decertarent ut non traderer Iudaeis; nunc autem meum regnum non est hinc.»

${ }^{37}$ Dixit itaque ei Pilatus: «Ergo rex es tu?» Respondit Iesus: «Tu dicis, quia rex sum ego. Ego in hoc natus sum et ad hoc veni in mundum, ut testimonium perhibeam veritati; omnis qui est ex veritate audit meam vocem.»

${ }^{38}$ Dicit ei Pilatus: "Quid est veritas?» Et cum hoc dixisset, iterum exivit ad Iudaeos et dicit eis: "Ego nullam invenio in eo causam.»

\section{VERSIÓN EN ESPAÑOL}

${ }^{R V A}{ }^{33}$ Entonces Pilato entró otra vez al Pretorio, llamó a Jesús y le dijo: «¿Eres tú el rey de los judíos?»

${ }^{34}$ Jesús le respondió: «¿Preguntas tú esto de ti mismo, o porque otros te lo han dicho de mí?»

${ }_{35}$ Pilato respondió: «¿Acaso soy yo judío? Tu propia nación y los principales sacerdotes te entregaron a mí. ¿Qué has hecho?»

${ }^{36}$ Contestó Jesús: «Mi reino no es de este mundo. Si mi reino fuera de este mundo, mis servidores pelearían para que yo no fuera entregado a los judíos. Ahora, pues, mi reino no es de aquí.»

${ }^{1}$ Novum Testamentum Graece, Nestle-Aland, $28^{\text {th }}$ Edition of the Greek New Testament, Stuttgart 2014.

${ }^{2}$ Biblia Sacra luxta Vulgatam Versionem, Roger Gryson, 5 ${ }^{\text {th }}$ Revised Edition, Stuttgart 2007.

${ }^{3}$ Santa Biblia Reina-Valera, 1989. 
${ }^{37}$ Entonces Pilato le dijo: «¿Así que tú eres rey?» Jesús respondió: «Tú dices que soy rey. Para esto yo he nacido y para esto he venido al mundo: para dar testimonio a la verdad. Todo aquel que es de la verdad oye mi voz."

${ }^{38}$ Le dijo Pilato: «¿Qué es la verdad?» Habiendo dicho esto, salió de nuevo a los judíos y les dijo: "Yo no hallo ningún delito en él.»

\section{VERSIÓN EN INGLÉS ${ }^{4}$}

${ }_{\text {NKJ } 33}$ Then Pilate entered the Praetorium again, called Jesus, and said to Him: «Are You the King of the Jews?»

${ }^{34}$ Jesus answered him: «Are you speaking for yourself about this, or did others tell you this concerning Me?»

${ }^{35}$ Pilate answered: «Am I a Jew? Your own nation and the chief priests have delivered You to me. What have You done?»

${ }^{36}$ Jesus answered: «My kingdom is not of this world. If My kingdom were of this world, My servants would fight, so that I should not be delivered to the Jews; but now My kingdom is not from here.»

${ }^{37}$ Pilate therefore said to Him: «Are You a king then?» Jesus answered, «You say rightly that I am a king. For this cause I was born, and for this cause I have come into the world, that I should bear witness to the truth. Everyone who is of the truth hears My voice.»

${ }^{38}$ Pilate said to Him: «What is truth?» And when he had said this, he went out again to the Jews, and said to them: «I find no fault in Him at all.»

\section{CONSIDERACIONES PREVIAS}

Cualquiera que, como docente, tenga la más mínima experiencia de haber intentado que un alumno de Educación Secundaria (ya sea en Latín de $4^{\circ}$ de la Obligatoria, o en Latín I y II o Griego I y II del Bachillerato) aprenda, bajo su guía y tutela, algo de las que suelen llamarse «lenguas muertas» (prácticamente asesinadas en las últimas reformas educativas ${ }^{5}$, defenestradas hasta tal punto que es imposible que un bachiller curse más de tres años de Latín, y muy difícil, no de iure, pero sí de facto, que curse dos de Griego) se habrá encontrado con impedimentos de todo tipo para que se cumpla el proceso de enseñanza-aprendizaje que se le encomendó.

${ }^{4}$ New King James Version, Thomas Nelson, Nashville, Tennessee 1982.

${ }^{5}$ Véase el Boletín Oficial de Canarias no 136, de 15 de Julio de 2016, en el que se establece el currículo de estas materias en la Educación Secundaria Obligatoria y el Bachillerato: la materia de Latín se oferta en $4^{\circ}$ de ESO (tres horas semanales) y $1^{\circ}$ y $2^{\circ}$ de Bachillerato (cuatro horas semanales); Griego no se oferta en la ESO, sino solo en Bachillerato, tanto en $1^{\circ}$ (tres horas) como en $2^{\circ}$ (cuatro), aunque de hecho, muchas veces, no llega ni siquiera a impartirse, porque se exige un mínimo de alumnado para formar grupo. 
Primero está la dificultad misma de la disciplina: siempre es difícil acceder al conocimiento de una lengua que no sea la materna, sobre todo para hablantes de lenguas que fueron (o son) francas o imperiales, como el español, el francés o el inglés; pero más aún si esa lengua (y esto le pasa al latín y al griego antiguo ${ }^{6}$ ya no se habla y solo nos llega escrita, y está ligada, además, a una cultura que, aunque constituya los cimientos de la nuestra, ya no es exactamente la nuestra ${ }^{7}$.

Agrava la cosa la reducción ya mencionada, creciente en las últimas décadas, de la presencia de estas materias en el horario lectivo de la Educación Secundaria. En el bachillerato antiguo, por ejemplo, en el anterior al ya también difunto BUP, un alumno de Ciencias cursaba dos años Latín, y uno de Letras cinco. Ahora hay que ser muy decididamente de Letras para cursar tres.

Por si fuera poco, cargan estas asignaturas con el sambenito (infundado, claro, calumnioso, pero, como cualquier prejuicio ideológico, muy influyente en la realidad) de inútiles, inservibles (frente a otras como Economía, Informática o Inglés, que gozan de buena prensa, que tienen a su favor la opinión pública, que ocupan puestos de privilegio en el ideal pedagógico dominante), de modo que el alumnado llega a clase, desde el primer día, con una actitud digamos que latino-resistente o fobohelénica.

Y en fin, que son materias, ambas, que necesitan, que exigen (como muchas otras) que la clase, el aula, sea un espacio en que se produzca un acto esencialmente oral y verdaderamente público, o sea, donde se hable y se escuche, donde nos atendamos y entendamos, lo cual, en estos tiempos de escandalosa hegemonía de pantallas, cañones e imágenes (y no significa esta afirmación que renunciemos a las muchas prestaciones y variopintos beneficios del empleo de las TIC como herramientas didácticas), resulta cada día más difícil.

Así que estamos seguros de que cualquier procedimiento pedagógico que sirva, verdaderamente, para mejorar la enseñanza de estas lenguas, será bien recibido por los que se dedican a la cuasi-heroica tarea de enseñarlas en los tiempos que corren.

Este modesto artículo pretende precisamente eso, presentarle al docente de lenguas clásicas, como recurso didáctico, el inmenso material que nos proporciona el Nuevo Testamento ${ }^{8}$, producido en griego koiné durante el siglo I de nuestra era, traducido luego, a finales del IV, al latín, y versionado, hoy día, en prácticamente todas las lenguas que se escriben en el mundo.

${ }^{6}$ Aunque la situación no es exactamente la misma en ambas lenguas: el latín se transmuta, por así decir, en un abanico de lenguas, las romances, y el griego antiguo evoluciona hasta el griego moderno, que sí se habla actualmente.

${ }^{7}$ Son innegables los aportes a nuestra cultura occidental, de base greco-latina, de otras tales como la judaica, la árabe, la germánica o la anglosajona.

${ }^{8}$ Los cuatro Evangelios, los Hechos de los Apóstoles, las Epistolas y el Apocalipsis. 
$Y$ no es que, como cualquiera pueda pensar de entrada en esta España de nuestras culpas, en la que, hasta hace poco, la enseñanza del latín y el griego estaba ligada todavía a lo eclesiástico, queramos hacer proselitismo o catequesis en pro de las Sagradas Escrituras. Nos interesa el Nuevo Testamento más bien con fines pedagógicos, en cuanto que contiene producciones lingüísticas no demasiado difíciles. Hay que tener en cuenta que, cuando se escribieron los textos que constituyen el corpus al que nos referimos, sus autores, judíos helenizados, los formularon en griego koiné, la lengua franca, la lengua de cultura de ese momento, porque pretendían llegar a todo el mundo, tenían vocación universalista, ecuménica. De manera parecida a como se redacta ahora mismo en inglés sencillo y standard, para su divulgación universal, por ejemplo, el abstract de un artículo como este. Y más aún: cuando, a finales del siglo IV, Jerónimo de Estridón, por encargo del papa Dámaso I, abordó la titánica tarea de traducir al latín el Antiguo y el Nuevo Testamento, adoptó como lengua de llegada un latín corriente (de ahí que se conozca como Vulgata), que posibilitara el acceso del común de los mortales (en la parte occidental del imperio romano entonces casi nadie sabía ya griego) a las Sagradas Escrituras.

Lo cierto es que, ya desde su nacimiento en griego (y su «renacimiento» en latín), se caracterizan estos textos por su sencillez estilística, su sobriedad expresiva, su falta de aparato retórico, empaque literario y pretensiones artísticas; por lo que resultan mucho más accesibles para el principiante que un pasaje de Julio César, Cicerón, Plinio, Eutropio, Jenofonte o Tucídides, por poner algunos ejemplos de producciones en latín y en griego que, aunque aliviadas de dificultades, "arregladas», el sistema educativo pretende que el alumno de Bachillerato analice y traduzca en la prueba de EBAU. Que se sepa, a pesar de las horas sin cuento que, en Primaria y Secundaria, suelen dedicarse a la enseñanza del inglés (la lengua imperial ahora dominante), no se exige que un bachiller lea a Shakespeare en lengua original.

Hay que hacer pues (decíamos) un esfuerzo, en la cuna sacrosanta de la Contrarreforma, para vencer prejuicios comprensibles, pero perjudiciales en la medida en que nos impiden el uso de un instrumento didáctico muy rentable, muy útil para nuestros fines. Es más, podríamos hasta aprovechar, como se dice en el kárate, la fuerza del enemigo a nuestro favor: dado que el referente de muchos pasajes seguro que resulta conocido a nuestros alumnos, tal circunstancia puede favorecer el acercamiento a la lengua en que están escritos.

$\mathrm{Si}$ se pretendiera, de verdad, que el currículo fuera coherente y provechoso, el uso del Nuevo Testamento como instrumento didáctico permitiría, por ejemplo, que un alumno de Letras, que estudiara entrambas lenguas muertas, analizara y tradujera del latín un fragmento como el que encabeza este artículo, y que, en el curso siguiente, lo leyera en griego, recorriendo un muy interesante camino inverso al orden cronológico de su producción.

\section{UTILIDADES DIDÁCTICAS DE ESTE PASAJE}

Pero vamos a bajar a la arena, a entrar en materia, a explicar cómo podrían vertebrarse, mediante fragmentos como este del evangelio de Juan, los contenidos 
de ambas materias, Latín y Griego, tanto en lo que se refiere a cuestiones estrictamente gramaticales (fonético-fonológicas, pragmáticas, léxicas, morfosintácticas) como en lo que atañe a otras que podríamos llamar, en sentido amplio, «culturales» (léxico-semánticas, históricas, teológicas...) $)^{9}$.

\section{A. CONTENidos FOnÉTICO-FONOLÓGICOS: DE LA VISTA AL OÍDO}

Consideramos imprescindible, para el aprendizaje de cualquier lengua, muerta o viva, que la lengua suene, que el oído del alumno se haga, se acostumbre a ella, y su boca a pronunciarla. Así que, ya estemos en clase de latín o en clase de griego, un fragmento como este permitiría hacer ejercicios de lectura en voz alta, incluso dramatizada, como si jugáramos a hacer teatro radiofónico: un alumno haría de Pilato, otro de Jesús de Nazaret, y otro de narrador. Y así, por grupos de tres, harían sonar el pasaje, hasta que, por repetición, resonara en los oídos de toda la clase, resucitado, revivido desde el sarcófago de la escritura.

Puede parecer un dispendio de energía, una pérdida de tiempo, gastar esfuerzos en aprender a leer en voz alta latín o griego antiguo, pero la experiencia docente nos dice que, si el alumno está familiarizado de oído con los sonidos propios, los fonemas, de una lengua (también vale la recomendación, por supuesto, para las lenguas vivas, las que se hablan), tiene mucho más fácil y expedito el acceso a sus contenidos morfo-sintácticos y léxico-semánticos.

Pongamos un ejemplo referido a este pasaje, en el supuesto de que lo usáramos en la materia de Latín de $4^{\circ}$ de Educación Secundaria Obligatoria o Latín I de Bachillerato: en español es muy raro que una palabra termine en -t (salvo casos de galicismos como 'carnet' o 'chalet', anglicismos como 'test' o 'internet', o latinismos como 'accesit' o 'deficit); en el fragmento considerado, en la versión de la Vulgata, hay casi una veintena de palabras que terminan en -t, además de algunas conjunciones como 'et' o 'ut'. Seguro que, si logramos que resuene el fragmento en los oídos del alumno, le será más fácil, un par de meses más tarde, aprender que en -t termina la tercera persona del singular de la voz activa de los verbos.

Lo mismo podría decirse de los finales en -m (las palabras que los presentan en español suelen ser precisamente latinajos como 'ultimatum', 'curriculum', 'requiem); en el pasaje pasan de veinte los casos de final de palabra en - $m$. Leerlo, repetirlo, hará más fácil después que el alumno aprenda las marcas de acusativo o una de las posibilidades morfológicas de la desinencia verbal de primera persona del singular.

${ }^{9}$ Nos referimos a contenidos que se contemplan en el currículo de la LOMCE de las materias de Latín de $4^{\circ}$ de ESO (criterios de evaluación 2, 3 y 7), Latín I (2, 3, 7 y 8), Latín II (1, 2, 3, 5, 6 y 7), Griego I (3, 4, 8, 9 y 10) y Griego II (1, 2, 3, 5, 6 y 7) de Bachillerato. 
Por hacer más completo el ejercicio referido a este apartado bien se podría leer el fragmento de la Vulgata con las normas de pronunciación del latín clásico y también con las del latín eclesiástico, constatando e inventariando las diferencias entre ambas.

\section{B. CONTENIDOS PRAGMÁTICOS, LÉXICOS Y MORFOSINTÁCTICOS: EL SENTIDO GRAMA-} TICAL DE LA FRASE

Está constituido el pasaje por veintidós frases ${ }^{10}$, la mayoría de ellas predicativas o enunciativas (dieciséis), las demás interrogativas (seis), parciales (dos) o totales (cuatro), en las que se producen palabras ${ }^{11}$ (de todos los valores léxicos y de todas las categorías morfosintácticas posibles) e índices ${ }^{12}$, tanto de relación entre palabras (preposiciones, conjunciones subordinantes, pronombres relativos), como de sucesión o suma (conjunciones coordinantes).

A través del texto se pueden pues definir, desde un punto de vista léxico, con meridiana claridad para un principiante, las diferencias entre palabras sémicas ${ }^{13}$ o dotadas de significado, y palabras asémicas, sin significado, pero con valores, tales como nombres propios ${ }^{14}$, mostrativos ${ }^{15}$, interrogativos ${ }^{16}$, cuantificadores $^{17}$, metafrásticos ${ }^{18}$, y cópula y otros verbos auxiliares ${ }^{19}$.

${ }^{10}$ Unidades de sentido, caracterizadas por una entonación, una melodía que las acota y caracteriza su modalidad, lo que la frase hace. El sentido de una frase sería una componenda entre su modalidad, el valor léxico de las palabras que la constituyen y las relaciones sintácticas que entre esas palabras se establecen.

${ }^{11}$ Conjuntos de fonemas dotados de acento, que pueden constituir frase por sí solas.

${ }^{12}$ Conjuntos de fonemas (o solo un fonema como en español las conjunciones ' $y$ ', 'o', o la preposición 'a’) no dotados de acento, que no pueden constituir frase por sí solos.

${ }^{13}$ Este término y los que siguen, correspondientes a la clasificación léxica de las palabras, obedecen a la nomenclatura usada en sus estudios (citados en la bibliografía aneja) de gramática general por A. García Calvo. Se entiende por 'sémicas' aquellas palabras que tienen 'significado', aquellas de cuyos referentes podemos hacernos una «idea», un dibujo mental, por ejemplo: praetorium, rex, veritas, invenio, audio. Asémicas serían las que no significan, sino que aportan al sentido de la frase otro tipo de valores léxicos; sirven para otras cosas, no para significar. (topónimos).

${ }^{14}$ Sirven para señalar personas (prosopónimos), como Iesus, Iudaeus, Pilatus, o lugares

${ }^{15}$ Sirven para señalar, como ego (me, mihi), ei (eo, eis), hoc, hinc, meum (mei, meam), nunc, tu (te, temet, tibi), tua.

${ }^{16}$ Sirven para preguntar, como quid.

${ }^{17}$ Sirven para contar, como alii, ipso, iterum, nullam, omnis.

${ }^{18}$ Sirven para negar o afirmar, como non, numquid.

${ }^{19}$ Sirven para juntar sujetos y atributos, como sum (es, est y esset), o para matizar aspectualmente otros verbos. 
Desde un punto de vista morfosintáctico, encontramos en el texto nombres ${ }^{20}$, pronombres $^{21}$, adjetivos ${ }^{22}$ y determinantes ${ }^{23}$, o sea, palabras de carácter nominal, declinables tanto en latín como en griego ${ }^{24}$, ambas lenguas flexivas; también verbos ${ }^{25}$, claro, conjugables; y adverbios ${ }^{26}$, invariables, todos asémicos en este fragmento.

Es relativamente fácil (estamos pensando en un novato en la materia, en un principiante de Latín de $4^{\circ}$ de Educación Secundaria Obligatoria, aunque bien podría servir el mismo planteamiento didáctico, mutatis mutandis exemplis, para uno de Griego I de Bachillerato) percibir, tras leer varias veces el texto, que hay palabras que varían, en su parte final, de terminación, de desinencia. Cualquiera puede inferir, sin saber nada, sin ningún conocimiento gramatical previo, por pura intuición, que Iesus y Iesum, Iudaeus, Indaeorum y Iudaeis, veritas, veritati y veritate, meum, mei y meam, ei, eo y eis, dicis y dicit, dixit, dixerunt y dixisset, es y est, son formas distintas de la misma palabra.

A partir de estos casos de flexión o de conjugación presentes en el texto, habría que explicar, por un lado, el concepto de caso, entendido como índice incorporado de relación sintáctica, propio, en latín (y en griego), de las palabras de carácter nominal; $y$, por otro, la oposición aspectual entre formas del tema de presente y formas del tema de perfecto (infectum frente a perfectum: dic- frente a dix-). Acaso sean estos los dos procedimientos gramaticales del latín más difíciles de entender para un hablante del español, por el hecho de que ya no rigen en nuestra lengua, a no ser de modo residual.

Las categorías de género y número (en nombres, adjetivos y determinantepronombres), de persona (en algunos pronombres), de persona, número, voz, tiempo y modo (en los verbos), son más fácilmente entendibles, puesto que se dan también en español y se marcan de manera parecida.

Las funciones de los casos están suficientemente representadas en el pasaje. Encontramos sujetos y atributos en nominativo ${ }^{27}$, complementos directos en acusativo $^{28}$, indirectos en dativo ${ }^{29}$, complementos del nombre en genitivo ${ }^{30}$, complementos

${ }^{20}$ En el fragmento considerado: causam, gens, ministri, mundo, pontifices, praetorium, regnum, rex, testimonium, veritas (veritati, veritate), vocem.

${ }^{21}$ En el fragmento: alii, ego (me, mihi), ei (eo, eis), hoc, quid, tu (te, temet, tibi).

${ }^{22}$ Solo uno, y asémico, Iudaeus: ya dijimos que es característica de estos textos la sobriedad expresiva.

${ }^{23}$ En el fragmento: hoc, ipso, meum (mei, meam), nullam, omnis, tuam.

${ }^{24}$ No añadimos los ejemplos en griego por no hacer las notas excesivamente engorrosas.

${ }^{25}$ En pretérito perfecto (dixerunt, dixit, exivit, fecisti, introivit, natus sum, respondit, tradiderunt, veni, vocavit) y presente (audit, dicis, dicit, invenio) de indicativo; pero también en subjuntivo: presente (perhibeam), imperfecto (decertarent, traderer), y pluscuamperfecto (dixisset).

${ }^{26}$ Estos cinco: hinc, iterum, non, numquid, nunc.

${ }^{27}$ Pilatus, tu, Iesus, alii, ego, gens tua, pontifices, regnum meum, ministri mei, omnis qui, veritas (de sujeto) y rex, Indaeus, quid (de atributo).

${ }_{28}^{28}$ Iesum, hoc, te, quid, testimonium, meam vocem, nullam causam.

${ }^{29}$ ei, mihi, Iudaeis, veritati, eis.

${ }^{30}$ Iudaeorum. 
circunstanciales en forma de adverbio ${ }^{31} \mathrm{o}$ de sintagmas preposicionales con acusativo $^{32}$ o ablativo ${ }^{33}$. No hay vocativos, ni ablativos sin preposición.

En lo que a sintaxis oracional se refiere, se producen en el texto (no hay ningún caso de yuxtaposición) coordinaciones copulativas (hasta en siete ocasiones se usa la conjunción et, sumando una frase con la anterior ${ }^{34}$, períodos verbales dentro de una misma frase ${ }^{35}$, o nombres que conforman un sujeto de doble núcleo ${ }^{36}$ ), disyuntivas (entre núcleos verbales de una misma frase ${ }^{37}$ ), adversativas (entre frases ${ }^{38}$ ) y conclusivas (también entre frases ${ }^{39}$ ). Solo faltaría el tipo de las explicativas, las que usan, en latín, las conjunciones nam y enim.

Y, en fin, seis casos de oraciones subordinadas: cuatro adverbiales: una condicional $^{40}$, una temporal de cum histórico ${ }^{41}$ y dos finales ${ }^{42}$; una adjetiva de relativo sustantivada $a^{43}$; y otra que, aunque parece una adverbial causal por la conjunción que se emplea en la versión de la Vulgata, quia, podría interpretarse (ya volveremos más adelante sobre esta cuestión), si atendemos al original griego, como sustantiva ${ }^{44}$.

C. CONTENidos léXiCO-SEMÁNTICOS: AQUELlO DE LO QUE LA LENGUA HABLA, LA REALIDAD REFERIDA

$\mathrm{Al}$ adolescente que se acerca por primera vez al estudio de una materia nueva, conviene demostrarle, hacerle evidente, desde el principio, que dicha materia le será útil para la vida, es decir, que lo que estudia en la escuela no es un pretexto inútil y estéril para entretenerle un tiempo vacío. En el caso del Latín y el Griego es imprescindible, como puede imaginarse, dada la mala prensa que padecen, tal demostración. Y no hay camino más rápido para ello que iniciar al alumno en el estudio de la etimología, del origen y evolución de las palabras, actividad que seguro que le ayuda

${ }^{31}$ binc, iterum, non, numquid, nunc.

${ }^{32}$ in praetorium, in hoc, ad hoc, in mundum, ad Iudaeos.

${ }_{33}$ a temet ipso, de me, de mundo hoc, ex hoc mundo, ex veritate, in eo.

${ }^{34}$ et respondit Iesus; et cum hoc...

${ }^{35}$ introivit... et vocavit Iesum et dixit ei; ego in hoc natus sum et ad hoc veni in mundum; ...iterum exivit ad Iudaeos et dicit eis.

${ }^{36}$ gens tua et pontifices.

${ }^{37}$ a temet ipso hoc dicis an alii tibi dixerunt de me?

${ }^{38}$ nunc autem meum regnum non est hinc.

${ }^{39}$ introivit ergo...; dixit itaque ei Pilatus; ergo rex es tu?

${ }^{40}$ si ex hoc mundo esset regnum meum, ministri mei...

${ }^{41}$ et cum hoc dixisset, iterum exivit...

${ }^{42}$... decertarent ut non traderer Iudaeis; ...veni in mundum, ut testimonium perhibeam veritati.

${ }^{4} 3$ omnis qui est ex veritate audit meam vocem.

${ }^{44}$ tu dicis, quia rex sum ego. 
a ampliar y usar con precisión el vocabulario de su lengua materna (es inmenso el aporte léxico del latín y el griego al español), y en la que puede incluso encontrar placer, el goce del descubrimiento, el disfrute en el aprendizaje, que era de lo que se trataba.

Piénsese, en este sentido, en los recursos que un texto como este ofrece para la investigación etimológica, más completa y rica aún si comparamos las palabras latinas con sus correlatos griegos, y «jugamos» con ellos a encontrar en español derivados de los lexemas usados en ambas lenguas.

Sea, por ejemplo, el caso de $\pi \rho \alpha \iota \tau \omega ́ \rho ı ⿻ v$, , palabra de origen latino (praetorium) transcrita al griego, derivada de praetor (de prae-itor, lit. «el que va delante»), que significa en el texto algo así como "residencia del pretor», algo como "comisaría» (si hiciéramos una transferencia cultural). Podría servir para precisar el significado de sintagmas que se usan aún en español como 'guardia pretoriana', o explicar el origen de un topónimo como Pretoria, nombre de la capital de Sudáfrica.

Los términos rex/ regnum, en griego $\beta \alpha \sigma l \lambda \varepsilon \dot{v} \varsigma$ (basílica, Basilio)/ $\beta \alpha \sigma i \lambda \varepsilon i \alpha$, y su relación morfosemántica con el verbo regere ('gobernar', 'regir'), o el adjetivo rectus, permiten indagar en el significado preciso de palabras del español tales como 'rey', 'reino', 'real', 'realeza', pero también de las más cultas 'regalía', 'regencia', 'regente', 'dirigente', 'dirigir', 'dirección', 'corrección', 'corregir', 'erigir', 'rector'...

De sumo interés léxico-semántico (nos limitamos a citar las posibilidades, por aligerar el conjunto: no hace falta una explicación pormenorizada de cada lexema para cumplir el propósito de este artículo) son también las duplas gens (gen, género, genético, genital, Génesis, congénito, transgénico, ingenuo...)/ Ě $\theta v o \varsigma$ (etnia, étnico,

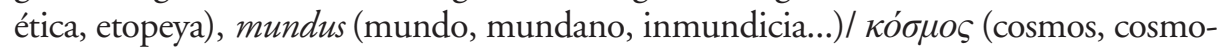
logía, cosmética...), veritas (verdad, verosímil...)/ $\alpha \lambda \eta \dot{\eta} \theta \varepsilon \imath \alpha$ (lit. 'des-cubrimiento', 'no-ocultación', Alicia), vox (voz, vocal, vocálico, vocalista, Vox)/ $\varphi \omega v \eta$ (fonética, fonología, fonema, micrófono, afonía, teléfono, megáfono, foniatra, iphone...), testi-

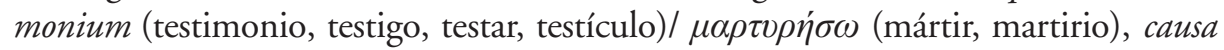
(causa, cosa, acusar, acusativo)/ aitía (etiología), audio (audio, auditivo, oír)/ $\dot{\alpha} \kappa o v ́ \omega$

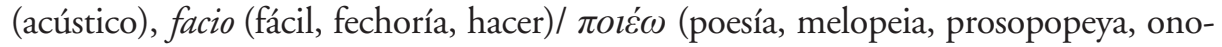

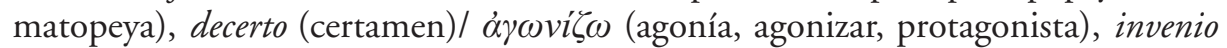

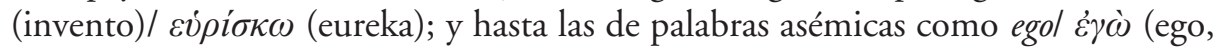

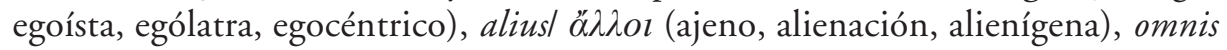
(omnívoro, omnipotente, omnisciente)/ $\pi \tilde{\alpha} \varsigma$ (panteísmo, panorama, pantomima) o nullus (nulo, nulidad, anular)/ ovidsís.

Puede despertar la curiosidad del alumno investigar el significado de palabras como pontifex, lit. 'el que hace el puente' (compuesta, formada por juntura de dos lexemas, como su correlato griego 'o̊ $\rho \imath \imath \rho \varepsilon \tilde{\iota} \varsigma$ ', lit. 'supersacerdote'), o minister, origen de la nuestra 'ministro', que significa en latín algo como 'sirviente', 'servidor', 'ayudante', 'asistente'.

Las formas verbales tradiderunt $(\pi \alpha \rho \varepsilon \delta \delta \omega \kappa \alpha \dot{v})$, traderer $(\pi \alpha \rho \alpha \delta o \theta \tilde{\omega})$, que comparten lexema por cierto con nuestra palabra 'tradición', introivit ( $\varepsilon i \sigma \tilde{\eta} \lambda \theta \varepsilon v$ ) y exivit $\left(\dot{\varepsilon} \xi \tilde{\eta} \lambda \theta_{\varepsilon v}\right)$ permiten asomarse a la rentabilidad semántica de los preverbios. 
Los judíos, Pilato y Jesús, un gentilicio y dos prosopónimos, son los nombres propios que aparecen en el pasaje, y merecerían, por tanto, en un análisis cabal del fragmento, una glosa. Podemos aprovechar la circunstancia para hablar de la figura de Jesús no desde un punto de vista teológico, como hijo de Dios, enviado al mundo por el Padre Eterno para redimir a los hombres del pecado y la muerte, sino como un judío rebelde con causa, líder de un grupo (ministri mei), entregado por los suyos (gens tua) y sus autoridades religiosas (pontifices) a las fuerzas de ocupación romanas en Judea, en concreto al prefecto Pilato, la mayor autoridad de esta siempre conflictiva provincia imperial. Siempre hubo crisis política en la zona, como la sigue habiendo ahora en Israel. Adviértase que este tipo de relaciones, conexiones, o referencias, son fundamentales para que un adolescente del siglo XXI se interese por la materia.

Y podrían, como colofón al estudio del pasaje, plantearse cuestiones teológicas de importancia que nos sugiere el fragmento, y que permiten, de paso, prestigiar el análisis filológico y la competencia lingüística para leer los textos originales, a la vez que se pone de manifiesto que traducir no es más que una tarea técnica, susceptible, por tanto, de incurrir en errores e imprecisiones que terminan afectando a la realidad y la ideología que la sustenta. Reflexiónese, por ejemplo, sobre el sentido, un tanto enigmático a nuestro entender, de dos frases, puestas por el evangelista una en boca de Jesús y otra en boca de Pilato.

Cuando Pilato le pregunta al nazareno si es rey, este le responde, en el original

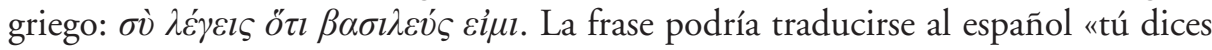
que soy rey» (tal como propone la Reina-Valera), que, a su vez, puede entenderse bien en el sentido de 'tú eres el que está diciendo que yo soy rey (yo no he dicho nada)' o, como parece que lo interpreta la traducción del inglés que presentamos, 'tú dices con razón que yo soy rey'. Más cerca de este segundo sentido parece que se sitúa la interpretación de Jerónimo en la Vulgata: tu dicis, quia rex sum ego, que habría que traducir como 'tú lo dices porque yo soy rey'. Y de un sentido al otro, como puede verse (o mejor dicho oírse) va mucho.

La otra frase a la que nos referimos es esta: cuando Jesús le dice a Pilato que él ha nacido para dar testimonio de la verdad y que todo el que "es de la verdad» escucha su voz, el prefecto, un tanto desconcertado, le pregunta: $\tau i \dot{\varepsilon} \sigma \tau \imath l v \dot{\alpha} \lambda \dot{\eta} \theta \varepsilon \imath \alpha$; (en la versión latina: quid est veritas?). El sentido de la frase tampoco se nos aparece nítido del todo. La traducción al español "¿qué es la verdad?», puede, de hecho, interpretarse en dos sentidos distintos: '¿cuál es la verdad?', '¿qué es lo verdadero?', '¿qué es verdad?' (lo que dicen de ti los que te acusan, o lo que dices tú), si se toma 'verdad' como atributo; o bien '¿a qué te refieres cuando dices «verdad»?, '¿qué es esa verdad de la que hablas?', si se toma 'verdad' como sujeto.

Lo más importante es que, al plantear estos dos problemas, que podríamos considerar de tipo filológico-teológico (y que no tenemos por qué resolver para 
cumplir nuestro objetivo docente), seguro que sembramos en el alumno cierto interés por la apasionante (y siempre controvertida) tarea de la traducción entre lenguas.

\section{OTRA VERSIÓN EN ESPAÑOL}

De hecho no estaría de más terminar el estudio del pasaje con una versión al español, que se hiciera eco, en lo posible, de lo que hayamos descubierto en el proceso de análisis del texto desde diversos puntos de vista. Como por ejemplo esta, fruto de nuestras reflexiones gramaticales sobre el sentido del fragmento:

\footnotetext{
${ }^{33}$ Entró entonces otra vez Pilato en el pretorio, y llamó a Jesús y le dijo: «¿ंTú eres el rey de los judíos?»

${ }^{34}$ Jesús respondió: «iPor ti mismo dices tú eso o te lo han dicho otros de mí?»

${ }^{35}$ Pilato respondió: «¿ Soy yo acaso judío? Tu gente y los sumos sacerdotes te entregaron a mí. ¿Qué has hecho?»

${ }^{36}$ Jesús respondió: «Mi reino no es de este mundo. Si mi reino fuera de este mundo, mis colaboradores lucharían para que no fuera entregado a los judíos. Pero ahora mi reino no es de aquí.»

${ }^{37}$ Pilato le dijo entonces: «¿Así que tú eres rey?» Jesús respondió: «Tú dices que soy rey. Yo nací para esto y vine al mundo para esto: para dar testimonio de la verdad. Todo el que es de la verdad escucha mi voz.»

${ }^{38}$ Pilato le dice: «¿QQué es la verdad?» Y tras decir esto, se dirigió de nuevo a los judíos y les dice: «Yo no encuentro en él delito alguno.»
}

\section{UN PROBLEMA DE GESTIÓN DE RECURSOS}

Queda pues mostrado y demostrado el rendimiento didáctico de un pasaje de seis versículos del capítulo 18 del evangelio de Juan para la enseñanza del latín y el griego. A través del texto hemos abordado ejercicios de lectura en voz alta, análisis pragmático, léxico, morfosintáctico, semántico, cuestiones de etimología, filológicas propiamente dichas, teológicas, históricas y culturales en general, con la intención, siempre presente, de suscitar el interés del alumnado por la materia, en cuanto que enseña algo útil para la vida fuera del aula. Por supuesto que cabría ampliar el número de traducciones (al francés, por ejemplo, al alemán), con lo que el procedimiento resultaría, por interdisciplinar, más rentable aún.

Como pasa en otros muchos ámbitos en este nuestro mundo occidental, el principal problema al que nos enfrentamos no es la falta de recursos, que, dicho sea de paso, nos sobran, sino a nuestra incapacidad para gestionarlos. Bastaría (pensamos) con elegir, para un primer curso de Latín o de Griego, tres pasajes como este (las posibilidades que el Nuevo Testamento ofrece son infinitas), uno por trimestre, que conformaran, debidamente graduados conforme a sus dificultades técnicas, algo así como la tercera parte de una antología de textos fabricada por el profesor. Las otras dos partes no debieran conformarse con textos de la tradición cristiana: las producciones 
más fáciles de Fedro ${ }^{45}$, Marcial $^{46}$ y Eutropio ${ }^{47}$ (en latín), Esopo y Apolodoro ${ }^{48}$ (en griego) proporcionarían otro tercio de los textos; y sentencias, máximas, frases sapienciales de diversos autores, en ambas lenguas, que vienen a ser como perlas, como piedras preciosas del pensamiento occidental, podrían constituir la otra tercera parte ${ }^{49}$.

Así, mediante antologías como la descrita, además de, tal como nos dicta el sentido común, estudiar estas ilustres lenguas muertas a través de los frutos que la escritura nos ha conservado a través de los siglos, evitaríamos, de paso, recurrir a textos fabricados (como si no hubiera producciones originales a patadas), ñoños e insulsos, que aburren a las piedras (los jóvenes son jóvenes, pero no estúpidos); o vernos obligados a «deshuesar» (aligerar de dificultades: lo cual no deja de sentirse como una falsificación, un timo, una estafa) textos originales muy difíciles; o fomentar, como material didáctico principal, el uso del libro de texto, que el alumno termina sintiendo como una indigesta miscelánea henchida de información que, a la postre, entorpece su aprendizaje, mata su curiosidad e impide, en consecuencia, su acercamiento a estas dos lenguas clásicas, pilares de la cultura greco-latina, base fundacional de la nuestra.

RECIBIDO: agosto 2019; ACEPTADO: octubre 2019.

\section{REFERENCIAS BIBLIOGRÁFICAS}

BAUER, W. (1971): Wörterbuch zum Neuen Testament, Berlín-Nueva York.

Berenguer Amenós, J. (1986): Gramática griega, Barcelona.

BW = BibleWorks 10 (2015), BibleWorks LLC [BibleWorks 7 (2003). Software for Biblical Exegesis and Research, BibleWorks, Virginia].

García Calvo, A. (1979): Del lenguaje, Zamora.

García Calvo, A. (1983): De la construcción, Zamora.

García Calvo, A. (1989): Hablando de lo que habla, Zamora.

Mateos, J.-SchÖKel, L. A. (1987²/20104): Nuevo Testamento, Madrid.

${ }^{45}$ Fabulae Aesopiae, I, 4 y 7, IV, 3, 10, 21 y 24.

${ }^{46}$ Epigrammata, I, 32, 38, 47, 63 y 64, III, 8 y 39, IV, 36, v, 43, 45 y 81, VI, 60, VII, 60 y 77, VIII, 74, XI, 64, 92 y 101, XII, 12, 16, 19, 20, 46 y 88.

${ }^{47}$ Breviarium, I, 2-8. Fragmentos referidos a los siete reyes de Roma.

${ }^{48}$ Véase la selección de textos (26 fábulas de Esopo y 28 fragmentos de Apolodoro) de estos dos autores griegos elaborada, como recursos para la prueba de EBAU en la Comunidad Autónoma de Canarias, por una comisión de profesores de la materia.

${ }^{49}$ Por ejemplo de la colección de sentencias de la Edad Media, en latín, recopiladas en 1920 por H. Walther. 
NA28 = Nestle, E. - Aland, K. (eds.) (2012): Novum Testamentum Graece, Stuttgart $\left[28^{\text {th }}\right.$ revised edition].

Piñero Sáenz, A. (ed.) (1995): Orígenes del cristianismo. Antecedentes y primeros pasos, Madrid.

PIÑERO, A. - PelÁEZ, J. (1995): El Nuevo Testamento. Introducción a los primeros escritos escritos cristianos, Córdoba.

Sebastián Yarza, F. I. (1972): Diccionario Griego-Español, Barcelona.

ZERWICK, M. (1997): El griego del Nuevo Testamento, Estella (Navarra). 